358

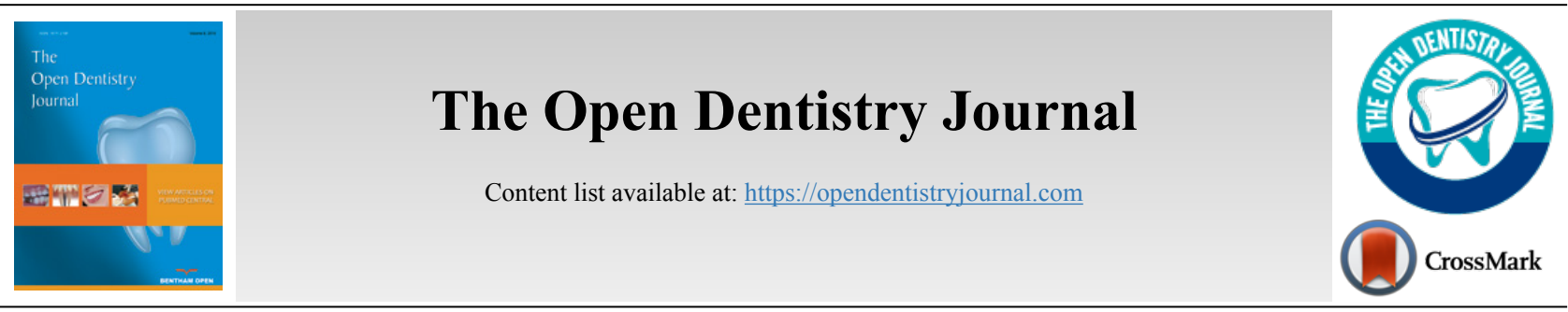

RESEARCH ARTICLE

\title{
Validation of Modified Dental Anxiety Scale for Dental Extraction Procedure (MDAS-DEP)
}

\author{
Tantry Maulina, ${ }^{1, *}$, Salma Nadiyah Ridho ${ }^{1}$ and Farah Asnely Putri ${ }^{1}$ \\ ${ }^{1}$ Department of Oral Surgery, Faculty of Dentistry, Universitas Padjadjaran, Bandung, Indonesia
}

\begin{abstract}
:
Background:

Dental anxiety remains a common problem encountered amongst those who are going to have a dental extraction procedure.

Objective:

The objective of the current study was to test the validity and reliability of the modified dental anxiety scale for dental extraction procedure (MDAS-DEP).

Methods:

The current study was conducted by using a cross-sectional survey method on one hundred and thirty-two (69 female; 63 male) participants who were about to go through the dental extraction procedure. A modified version of the MDAS was used in the current study. The questions of the original MDAS were replaced by specific questions about the dental extraction procedure, accompanied by five Likert-type answers. Reliability was measured by referring to the Cronbach's alpha value whilst construct validity was measured by using Pearson's correlation.
\end{abstract}

Results:

The analysis of the current study showed a Cronbach's alpha value of 0.822 Whilst the Pearson's correlation analysis revealed that all questions were proven to be valid, with the highest $\mathrm{r}$ value gained by question number $5(\mathrm{r}=0.817, p<0.01)$.

Conclusion:

The current scale was proven to be valid and reliable to be used as a specific scale to measure dental anxiety due to dental extraction.

Keywords: Dental anxiety, Anxiety, Dental extraction, Dental anxiety scale, Tooth removal, Third molar removal.

\begin{tabular}{|c|c|c|}
\hline Article History & Received: July 04, 2019 & Revised: August 27, 2019 \\
\hline
\end{tabular}

\section{INTRODUCTION}

Dental extraction or tooth removal especially third molar removal has been known for its effect on dental anxiety. Amongst the various dental treatment procedure, this particular measure is known for its effect in inducing dental anxiety to its highest level, [1 - 3] which might be due to the fact that this particular procedure involves the usage of a syringe as part of the anesthesia procedure as well as the usage of a rotary instrument(s) [2]. The fact that bone removal, as well as tooth sectioning, might also be a part of the procedure might also in-

* Address correspondence to this author at Department of Oral Surgery, Faculty of Dentistry, Universitas Padjadjaran - Bandung, Indonesia; Tel: +628211 5513030; E-mails: tantry.maulina@fkg.unpad.ac.id or tmau4292@uni.sydney.edu.au crease the patient's anxiety before the procedure. Regardless of the causing factors, dental anxiety during dental extraction or third molar removal procedure has the potential to prolong treatment duration, increase the level of extraction difficulty, as well as the possibility of increased post-operative pain [1].

In regards to dental anxiety evaluation, the usage of the Modified Dental Anxiety Scale (MDAS) in the previous studies as a valid tool to measure dental anxiety has been wellacknowledged, [4 - 6] not to mention the fact that it has been translated into several languages and tested for its validation as well as reliability. The MDAS is a five items scale that evaluates patient's anxiety through the question of (1) the patient's feeling about their upcoming dental treatment; (2) the patient's feeling while waiting in the waiting room; (3) the 
patient's feeling about having their tooth drilled; (4) the patient's feeling about having their teeth scaled and polished; and (5) the patient's feeling about having an injection in their upper back tooth gum. All five questions are provided with five Likert scale answers, which are "not anxious", "slightly anxious", "fairly anxious", "very anxious", and "extremely anxious". [4, 7]

Yet, even though the MDAS is a valid dental anxiety measure, it does not measure anxiety particularly induced by dental extraction or third molar removal procedure. Considering the effects, to be able to identify certain factors that contribute highly to the patient's anxiety who is about to go through dental extraction or third molar removal procedure will enable the operator to minimize patient exposure to that particular factor(s). To be able to achieve that, a particular dental anxiety scale that identifies factors that might contribute to dental extraction or third molar removal procedure is considered to be of importance. Therefore, a modification to the MDAS was performed. In regards to the modification and changes applied to the questions of the scale, it has to be tested for validity and reliability before it can be used accordingly. The aim of the current study was, therefore, to test the validity as well as reliability of the Dental Anxiety Scale for Dental Extraction Procedure (MDAS-DEP).

\section{MATERIALS AND METHODS}

The current study recruited one hundred and thirty-two (69 female: 63 male) participants that agreed to participate and visited the Oral and Maxillofacial Minor Surgery Outpatient Clinics at the Unpad Dental Hospital. Prior to the start of the study, ethical clearance was gained from the Universitas Padjadjaran Research Ethics Committee. To confirm, every procedure and ethical aspect of the current research has been conducted in full accordance with the World Medical Association Declaration of Helsinki and that all participants gave written consent for their participation in the current study. As required, all participants signed an informed consent prior to their participation in the current study.

Participants recruited in the current study were recruited based on the following inclusion criteria: 1) no previous experience of tooth removal (or surgical) procedure; 2) no history of local anesthesia procedure; and 3) aged between 18 to 45 years old. All eligible participants were then given an explanation by the field researcher about the aim of the study, as well as, an instruction on how to fill the questionnaire. Once the participant agreed to participate and signed an informed consent, the participant was asked to fill in the questionnaire. All data was collected by the field researcher.

\subsection{Sample Size Calculation}

There are several recommendations from the previous studies that can be used as sample size calculation guidelines, of which a respondent-to-item ratio is used and can range from 5:1 (5 respondents for one item in the questionnaire, which means a 10 item-questionnaire should have 50 respondents) [8] to $15: 1$ to $30: 1$ [9]. The current study used the $15: 1$ comparison ratio, yet, as larger samples are always better than smaller samples, [10] and there are no absolute rules for the number of samples needed for questionnaire validation [11], the authors of the current study agreed to utilize as many sample as possible in the current study and finally utilized 132 participants as our sample.

\subsection{Modified Dental Anxiety Scale for Dental Extraction Procedure (MDAS-DEP)}

The MDAS-DEP consists of five questions, which are (1) If you were told that one of your teeth had to be extracted, how would you feel; (2) If you were about to go to the dentist tomorrow to have your tooth extracted, how would you feel; (3) If you were sitting in the waiting room waiting for your dental extraction procedure, how would you feel; (4) If you were about to get a local anesthesia injection in your gum, how would you feel; and (5) If your third molar was about to be removed through a surgical procedure, how would you feel. As for the answer, the five Likert-scale answers used in the MDAS-DEP are the same answers used in the original MDAS (Fig. 1). Therefore, the grading system, as well as the cutoff point, are similar to the original MDAS [7].

\subsection{Reliability}

The reliability of a tool refers to the degree of how well a measurement tool or a procedure can be replicated [12 - 14]. There are three components of reliability, which are equivalence, stability, and internal consistency [12]. In the current study, the internal consistency of the scale was mea-sured by calculating Cronbach's alpha value. The concept of alpha was first developed by Lee Cronbach in 1951 and expressed by a value between 0 to 1 . In regards to reliability, it is important to note that the value of Cronbach's alpha will increase if the item being tested is correlated highly to each other. Yet, a high value of Cronbach's alpha does not necessarily mean that the scale or the instrument being tested has high internal consistency, as internal consistency is also affected by the length of the scale. A short scale will reveal a reduced alpha value [15].

\subsection{Validity}

Validity testing of a research instrument is intended to test whether the instrument used in the study can measure what is intended to be measured. There are several types of validity, namely, face validity, construct validity, content validity, and criterion validity $[12-14,16]$. In the current study, there were two types of validity being evaluated, the face validity that involved several experts, as well as the construct validity of the scale that was tested by using Pearson's correlation [17, 18]. The result of Pearson's correlation, the $r$ value, will be compared by the $r$ value from the $r$ table. As the $p$ value of the current study is set to be at $p<0.01$, then the r-table for 132 participants was 0.224 . Should the $r$ value of the tested question be higher than the $r$ table, the item is considered as valid.

\subsection{Statistical Analysis}

Construct validity and reliability of the tested items in the current study were analyzed by using the IBM SPSS statistic version 23 . 


\section{RESULTS}

The current study used the 132 participants that aged between 18 to 45 -year old that were about to go through tooth removal procedure. Demographical characteristics of the participants can be viewed in Table $\mathbf{1}$. The analysis of the current study revealed that the Cronbach's alpha value (to test the reliability) of the scale was 0.822 . Therefore, it can be concluded that the scale is proven to be robust with high internal consistency, as the acceptable Cronbach's alpha was reported to be somewhere between 0.70 to 0.95 and the closer the number to 1 , the greater the internal consistency $[15,19$, 20]. As for the validity of the scale, it was tested by conducting the Pearson's correlation analysis. Prior to the conduction of the test, the degree of freedom (df) was set at 130, considering that the number of participants was $132(\mathrm{df}=\mathrm{N}-2)$. Therefore, the $\mathrm{r}$ value for a df of 130 with a significance level of 0.01 was 0.224 (original value $=0.2235$ ). The complete $r$ value of the scale, as well as the significance level can $r$ value for a df of 130 with a significance level of 0.01 was 0.224 (original value $=0.2235$ ). The complete $r$ value of the scale, as well as the significance level can be viewed in Table 2 .

Table 1. Proportion of participants based on demographical characteristics.

\begin{tabular}{|c|c|c|}
\hline Variable & \multicolumn{2}{|c|}{ Categories } \\
\hline \multirow{3}{*}{ Sex } & Male & Female \\
\cline { 2 - 3 } & 63 & 69 \\
& $47.72 \%$ & $52,27 \%$ \\
\hline \multirow{2}{*}{ Age } & 18 to 30 yo* & 31 to 45 yo \\
\cline { 2 - 3 } & 103 & 29 \\
& $78,03 \%$ & $21,97 \%$ \\
\hline
\end{tabular}

*year old

Table 2. The results of the Pearson's correlation and Cronbach's alpha deleted item calculation for the MDAS-DEP.

\begin{tabular}{|c|c|c|c|c|}
\hline Item & r Value & r Table & $\boldsymbol{p}$ Value* & Cronbach's Alpha if Item Deleted \\
\hline Question number 1 & 0.771 & & $<0.01$ & 0.777 \\
\hline Question number 2 & 0.785 & & $<0.01$ & 0.772 \\
\hline Question number 3 & 0.711 & \multirow{2}{*}{0.224} & $<0.01$ & 0.799 \\
\hline Question number 4 & 0.724 & & $<0.01$ & 0.810 \\
\hline Question number 5 & 0.817 & & $<0.01$ & 0.774 \\
\hline
\end{tabular}

*significance level $=0.01, \mathrm{n}=132 ; \mathrm{df}=130$

\section{Modified Dental Anxiety Scale for Dental Extraction Procedure (MDAS-DEP)}

Name :

Age :

Sex

Can you tell us how anxious you get, if at all, about a dental extraction procedure? Please indicate by ticking $(\sqrt{ })$ the appropriate box.

1. If you were told that one of your teeth had to be extracted, how would you feel?

- not anxious • slightly anxious • fairly anxious • very anxious • extremely anxious

2. If you were about to go to the dentist tomorrow to have your tooth extracted, how would you feel?

- not anxious - slightly anxious - fairly anxious - very anxious • extremely anxious

3. If you were sitting in the waiting room waiting for your dental extraction procedure, how would you feel?

- not anxious - slightly anxious - fairly anxious $\bullet$ very anxious $\bullet$ extremely anxious

4. If you were about to get a local anesthesia injection in the gum, how would you feel?

- not anxious - slightly anxious $\bullet$ fairly anxious $\bullet$ very anxious $\bullet$ extremely anxious

5. If your third molar was about to be removed through a surgical procedure, how would you feel?

- not anxious - slightly anxious - fairly anxious - very anxious • extremely anxious

Fig. (1). Modified Dental Anxiety Scale for Dental Extraction Procedure (MDAS-DEP). 
Table 3. Distribution of participants based on the Likert-type grading system for every question of the MDAS-DEP.

\begin{tabular}{|c|c|c|c|c|c|}
\hline \multirow{2}{*}{ Question } & \multicolumn{5}{|c|}{ Number of Participants Based on Likert Grading System } \\
\cline { 2 - 6 } & Not Anxious & Slightly Anxious & Fairly Anxious & Very Anxious & Extremely Anxious \\
\hline \multirow{2}{*}{ Number 1 } & 21 & 67 & 40 & 4 & 0 \\
& $(15.5 \%)$ & $(50.8 \%)$ & $(30.3 \%)$ & $(3 \%)$ & $(0 \%)$ \\
\hline \multirow{2}{*}{ Number 2 } & 25 & 78 & 24 & 5 & 0 \\
& $(18.9 \%)$ & $(59.1 \%)$ & $(18.2 \%)$ & $(3.8 \%)$ & 0 \\
\hline \multirow{2}{*}{ Number 3 } & 23 & 68 & $(30.3 \%)$ & $(0.8)$ & $(0 \%)$ \\
\hline \multirow{2}{*}{ Number 4 } & $(17.4 \%)$ & $(51.5 \%)$ & 49 & 13 & 1 \\
& $(18.6 \%)$ & $(38.6 \%)$ & $(37.1 \%)$ & $(9.8 \%)$ & $(0.8)$ \\
\hline \multirow{2}{*}{ Number 5 } & 9 & 41 & 57 & 22 & 3 \\
& $(6.8 \%)$ & $(31.1 \%)$ & $(43.2 \%)$ & $(16.7 \%)$ & $(2.3 \%)$ \\
\hline
\end{tabular}

From Table 2, it was revealed that the questions of the MDAS-DEP showed a strong correlation ( $\mathrm{r}$ value $>0.700$ ) and were proven to be valid, as the $r$ value for every question was more than 0.224 . The highest $r$ value was shown by question number 5, which was: "If your third molar was about to be removed through a surgical procedure, how would you feel"? The significance level for all correlation was shown to be less than 0.01 , which means all questions were significantly correlated. An additional descriptive analysis that was performed to evaluate the distribution of the answers can be viewed in Table 3. It was revealed that for every question, participants were more likely to feel "fairly anxious", and the question that had most participants answered "very anxious" or "extremely anxious" was question number 5 , which is "If your third molar was about to be removed through a surgical procedure, how would you feel?".

\section{DISCUSSION}

The current study tested the validity and reliability of the modified dental anxiety scale for dental extraction procedure that was designed to enable the dental practitioner to identify whether the anxiety experienced by patients is due to dental extraction procedure (and its associated factors) that will be undertaken or due to fear of other dental procedure. To achieve the above mentioned, the scale has to be thoroughly and carefully evaluated before its utilization amongst the intended population. In the evaluation of a measurement tool such as a scale or a questionnaire, which is also known as the measurement tool development process, several key indicators that can be used, namely the validity and reliability of the tool. It is hoped that by going through such a process, measurements resulting from the measuring process will be accurate and that "measurement errors" can be minimized [21].

The validity, as previously mentioned can be differentiated into several types, which are face validity, construct validity, content validity, and criterion-related validity. The face validity of the current scale was tested by involving several experts in the area of oral surgery (oral surgeon), dental anxiety (trained dentist in the area of special care dentistry), and psychology (a psychologist) looking and reviewing the questions of the scale based on theoretical background. All experts in the current study agreed that the scale can validly measure what it was aimed at measuring. It is important to note that even though many experts do not consider this type of validity as an active measure of validity, face validity is one of the most used types of validity in developing countries. $[12,22]$ In regards to face validity, there are still some contradictories concerning this particular type of validity, therefore, another type of validity test is considered to be of important.

Once face validity evaluation was completed, construct validity evaluation was conducted and as previously mentioned, involved 132 (69 female; 63 male) patients who are about to undergo dental extraction or dental removal procedure. Different from the face validity, construct validity test evaluates the validity of a scale or a questionnaire by testing a hypothesis, and considered as the most valuable yet the most difficult type of validity measurement. [12, 23] Four factors are considered to be relevant to construct validity, namely convergent validity, discriminant validity, differentiation by known groups, and correlation analysis (which was the one that was used in the current study). [24] One of the correlation tests that can be used to measure construct validity is the Pearson's correlation, $[25,26]$, which has two important measurement indicators, the $\mathrm{r}$ value as well as the $p$ value. The higher the $\mathrm{r}$ value (correlation coefficient) is, the higher the correlation is; whilst a significant $p$ value indicates the significance of the correlation coefficient; which was the case in the current study, indicating the validity of the scale.

The current study used a Likert type of scale, which has been recognized as a self-reported measure and measured the participant's anxiety from the participant's point of view. This type of measurement scale has several advantages, such as (1) the simplicity, easiness, and certainty of the criteria; and (2) it allows the questions to have higher reliability than other types of scales [27]. It has been reported that using a summated response to multiple items such as the Likert scale has more stability as well as unbiased estimation compared to a response to a single item. This might be due to the fact that when responses to several single items are combined, the errors of the random measurement have the tendency to average out and therefore, provide better reliability for the measurement of the construct [28].

One of the concerns that arose when using multiple items scale such as the Likert-type scale is whether the width of the scale (the number of response types within each item) impacts the reliability of the scale. In regards to scale width, there have been several studies conducted to reveal the impact of scale width to reliability. [29 - 31] Unfortunately, no solid conclu- 
sion has been reached. In a study conducted by Bandalos and Enders [32], it was revealed that reliability increases with the number of scale points, yet, depending on the underlying distributions, the maximum reliability is obtained when a five or a seven response categories are used $[32,33]$. This particular reason might contribute to the high reliability of the current scale.

\subsection{Study Limitation}

The current study evaluated the validity as well as reliability of the MDAS-DEP questionnaire by evaluating the face validity, construct validity, and internal consistency as a component of reliability evaluation. Even though the abovementioned tests are considered to be adequate, additional validity, as well as reliability components tests (recommended for future study), would add valuable information. The utilization of more samples would also add more scientific value to the study.

\section{CONCLUSION}

To conclude, the results of the current study suggested that the MDAS-DEP is valid and reliable to be used as a measurement instrument for dental anxiety for patients who are about to undergo a dental extraction procedure.

\section{ETHICS APPROVAL AND CONSENT TO PARTI- CIPATE}

The study was approved by the Health Research Ethics Committee, Faculty of Medicine, Universitas Padjadjaran, Bandung, Indonesia (Number 211/UN6.C.10/PN/2017).

\section{HUMAN AND ANIMAL RIGHTS}

No animals were used in this research. All research procedures on humans were followed in accordance with the ethical standards of the committee responsible for human experimentation (institutional and national), and with the Helsinki Declaration of 1975, as revised in 2008 (http://www.wma.net/en/20activities/10ethics/10helsinki/).

\section{CONSENT FOR PUBLICATION}

The participants provided written informed consent to be involved in this study.

\section{STANDARDS OF REPORTING}

STROBE guidelines and methodology for observational study were followed.

\section{AVAILABILITY OF DATA AND MATERIALS}

The data supporting the findings of the article are available from the corresponding author on reasonable request.

\section{FUNDING}

$$
\text { None. }
$$

\section{CONFLICT OF INTEREST}

The authors declare no conflict of interest, financial or otherwise.

\section{ACKNOWLEDGEMENTS}

Declared none.

\section{REFERENCES}

[1] Wang T-F, Wu Y-T, Tseng C-F, Chou C. Associations between dental anxiety and postoperative pain following extraction of horizontally impacted wisdom teeth: A prospective observational study. Medicine 2017; 96(47)e8665

[http://dx.doi.org/10.1097/MD.0000000000008665]

[PMID: 29381942]

[2] Aznar-Arasa L, Figueiredo R, Valmaseda-Castellón E, Gay-Escoda C. Patient anxiety and surgical difficulty in impacted lower third molar extractions: A prospective cohort study. Int J Oral Maxillofac Surg 2014; 43(9): 1131-6.

[http://dx.doi.org/10.1016/j.ijom.2014.04.005] [PMID: 24837553]

[3] Tarazona B, Tarazona-Álvarez P, Peñarrocha-Oltra D, Rojo-Moreno J, Peñarrocha-Diago M. Anxiety before extraction of impacted lower third molars. Med Oral Patol Oral Cir Bucal 2015; 20(2): e246-50. [http://dx.doi.org/10.4317/medoral.20105] [PMID: 25662541]

[4] Humphris GM, Dyer TA, Robinson PG. The modified dental anxiety scale: UK general public population norms in 2008 with further psychometrics and effects of age. BMC Oral Health 2009; 9: 20. [http://dx.doi.org/10.1186/1472-6831-9-20] [PMID: 19709436]

[5] Amir A, Kamate S, Gupta P, Gupta A, Singh J, Singh S. Assessment of dental anxiety using MDAS (Modifed Dental Anxiety Scale) among students in Bareilly city - A cross sectional study. Int J Contemp Med Res 2018; 5: 1-3.

[6] Gremigni P, Mobilio N, Casu G, Catapano S. Validation of the Modified Dental Anxiety Scale (MDAS) in an Italian sample and invariance across gender and mode of administration. Eur J Psychol Assess 2014; 30: 140-9.

[http://dx.doi.org/10.1027/1015-5759/a000182]

[7] Humphris GM, Morrison T, Lindsay SJE. The modified dental anxiety scale: Validation and United Kingdom Norms. Community Dent Health 1995; 12(3): 143-50.

[PMID: 7584581]

[8] Gorusch RL. Factor analysis. $2^{\text {nd }}$ ed. Hillsdale, NJ: Lawrence Erlbaum Associates 1983.

[9] Pedhazur RJ. Multiple regression in behavioral research: Explanation and prediction. Fort Worth, TX: Harcourt Brace College Publishers 1997.

[10] Tsang S, Royse CF, Terkawi AS. Guidelines for developing, translating, and validating a questionnaire in perioperative and pain medicine. Saudi J Anaesth 2017; 11(Suppl. 1): S80-9.

[http://dx.doi.org/10.4103/sja.SJA_203_17] [PMID: 28616007]

[11] Osborne JW, Costello AB. Sample size and subject to item ratio in principal components analysis. Pract Assess, Res Eval 2004; 9: 1-9.

[12] Bolarinwa OA. Principles and methods of validity and reliability testing of questionnaires used in social and health science researches. Niger Postgrad Med J 2015; 22(4): 195-201.

[http://dx.doi.org/10.4103/1117-1936.173959] [PMID: 26776330]

[13] Wong KL, Ong SF, Kuek TY. Constructing a survey questionnaire to collect data on service quality of business academics. Eur J Soc Sci 2012; 29: 209-21.

[14] Taherdoost H. Validity and reliability of the research instrument: How to test the validation of a questionnaire/survey in a research. Int J Acad Res in Manage 2016; 5: 28-36.

[http://dx.doi.org/10.2139/ssrn.3205040]

[15] Tavakol M, Dennick R. Making sense of Cronbach's alpha. Int J Med Educ 2011; 2: 53-5.

[http://dx.doi.org/10.5116/ijme.4dfb.8dfd] [PMID: 28029643]

[16] Valim MD, Marziale MHP, Hayashida M, Rocha FLR, Santos JLF. Validity and reliability of the questionnaire for compliance with standard precaution. Rev Saude Publica 2015; 49: 1-8. [http://dx.doi.org/10.1590/S0034-8910.2015049005975] [PMID: 26759967]

[17] Sullivan GM, Artino AR Jr. Analyzing and interpreting data from likert-type scales. J Grad Med Educ 2013; 5(4): 541-2. [http://dx.doi.org/10.4300/JGME-5-4-18] [PMID: 24454995]

[18] Murray J. Likert Data: What to use, parametric or non-parametric? Int J Bus Soc Sci 2013; 4: 258-64.

[19] Gliem JA, Gliem RR. Calculating, interpreting, and reporting Cronbach's alpha reliability coefficient for Likert-type scales 2003.

[20] Taber KS. The use of Cronbach's Alpha when developing and reporting research instruments in science education. Res Sci Educ 
2018; 48: 1273-96.

[http://dx.doi.org/10.1007/s11165-016-9602-2]

[21] Kimberlin CL, Winterstein AG. Validity and reliability of measurement instruments used in research. Am J Health Syst Pharm 2008; 65(23): 2276-84.

[http://dx.doi.org/10.2146/ajhp070364] [PMID: 19020196]

[22] Sangoseni O, Hellman M, Hill C. Development and validation of a questionnaire to assess the effect of online learning on behaviors, attitude and clinical practices of physical therapists in the United States regarding evidence-based practice. Internet J Allied Health Sci Pract 2013; 11: 1-12.

[23] Strauss ME, Smith GT. Construct validity: advances in theory and methodology. Annu Rev Clin Psychol 2009; 5: 1-25. [http://dx.doi.org/10.1146/annurev.clinpsy.032408.153639] [PMID: 19086835]

[24] Boateng GO, Neilands TB, Frongillo EA, Melgar-Quiñonez HR, Young SL. Best practices for developing and validating scales for health, social, and behavioral research: A primer. Front Public Health 2018; 6: 149.

[http://dx.doi.org/10.3389/fpubh.2018.00149] [PMID: 29942800]

[25] de Laat FA, Rommers GM, Geertzen JH, Roorda LD. Construct validity and test-retest reliability of the questionnaire rising and sitting down in lower-limb amputees. Arch Phys Med Rehabil 2011; 92(8): 1305-10.

[http://dx.doi.org/10.1016/j.apmr.2011.03.016] [PMID: 21807151]
[26] Karras DJ. Statistical methodology: II. Reliability and validity assessment in study design, Part B. Acad Emerg Med 1997; 4(2): 144-7.

[http://dx.doi.org/10.1111/j.1553-2712.1997.tb03723.x] [PMID: 9043544]

[27] Chomeya R. Quality of psychology test between Likert scale 5 and 6 points. J Soc Sci 2010; 6: 399-403.

[http://dx.doi.org/10.3844/jssp.2010.399.403]

[28] Warmbrod JR. Reporting and interpreting scores derived from Likerttype scale. J Agric Educ 2014; 55: 30-47.

[http://dx.doi.org/10.5032/jae.2014.05030]

[29] Jacoby J, Matell MS. Three-point Likert scales are good enough. J Mark Res 1971; 8: 495-500.

[http://dx.doi.org/10.1177/002224377100800414]

[30] Aiken LR. Number of response categories and statistics on a teacher rating scale. Educ Psychol Meas 1983; 43: 397-401. [http://dx.doi.org/10.1177/001316448304300209]

[31] Churchill GA Jr, Peter JP. Research design effects on the reliability of rating scales: A meta-analysis. J Mark Res 1984; 21: 360-75. [http://dx.doi.org/10.1177/002224378402100402]

[32] Bandalos DL, Enders CK. The effects of non-normality and number of response categories on reliability. Appl Meas Educ 1996; 9: 151-60. [http://dx.doi.org/10.1207/s15324818ame0902 4]

[33] Felix R. The impact of scale width on responses for multi-item, selfreport measures. J Target Measure Analy Market 2011; 39: 153-64. [http://dx.doi.org/10.1057/jt.2011.16]

\section{(C) 2019 Maulina et al.}

This is an open access article distributed under the terms of the Creative Commons Attribution 4.0 International Public License (CC-BY 4.0), a copy of which is available at: (https://creativecommons.org/licenses/by/4.0/legalcode). This license permits unrestricted use, distribution, and reproduction in any medium, provided the original author and source are credited. 